\title{
COLONIZAÇÃO NATURAL POR ESPÉCIES NATIVAS E EXÓTICAS DAS ENCOSTAS DEGRADADAS DA SERRA DO MAR ${ }^{1}$
}

\author{
Nelson Augusto dos Santos Junior², Victor José Mendes Cardoso ${ }^{3}$, José Marcos Barbosa² e \\ Maurício Augusto Rodrigues ${ }^{2}$
}

\begin{abstract}
RESUMO - Os deslizamentos são eventos inerentes à dinâmica da Serra do Mar, nos trechos mais declivosos. Contudo, devido a alguns fatores de intervenção, como a poluição atmosférica, ocupação da base dos morros e outros, a incidência desses eventos tem aumentado. Diante disso, este estudo objetivou avaliar a dinâmica de colonização de áreas de encosta degradadas, como forma de subsidiar ações de recuperação. Para tanto, foram adotadas duas áreas experimentais, localizadas em trechos da serra do Mar próximos à Baixada Santista, onde foram lançadas parcelas de $1 \mathrm{~m}^{2}$ e obtidos dados fitossociológicos. Em seguida, as áreas foram limpas e os mesmos parâmetros da avaliação inicial, registrados, mensalmente, ao longo de um ano. Foram encontradas 20 espécies, pertencentes a 14 famílias botânicas, em sua maioria espécies exóticas ou nativas não regionais.
\end{abstract}

Palavras-chave: Deslizamento, Recuperação de encostas e Serra do Mar.

\section{STUDY OF THE NATURAL SETTLING OF HILLSIDES DEGRADED IN THE SERRA DO MAR}

\begin{abstract}
The landslides are inherent events to the dynamics of the Serra do Mar, in the stretches most declivous. However, some factors of intervention, such as atmospheric pollution, occupation of the base of the mounts, among others, increase the incidence of this event. Furthermore, the present study aimed to evaluate the settling dynamics of degraded areas of hillsides, aiming for a restoration. Two experimental areas were adopted, in stretches of the Serra do Mar, next to the Baixada Santista where parcels of one $m^{2}$ had been launched, and phytosociological data was obtained. After that, the areas were cleaned and the same parameters of the initial evaluation were registered, monthly, during 1 year. Twenty species were found, pertaining to 14 families, in its majority exotic or not-regional native species.
\end{abstract}

Keywords: Landslides, Recovery of hillslides and Serra do Mar.

\section{INTRODUÇÃO}

Durante o verão de 1985, fortes chuvas, associadas aos elevados índices de poluição atmosférica, propiciaram grandes deslizamentos na serra do Mar próximo de Cubatão, SP, que promoveram prejuízos consideráveis às indústrias e à população como um todo (POMPÉIA et al., 1989; SÃO PAULO, 1999). Essa ocorrência fez que surgissem algumas iniciativas no intuito de reduzir ou eliminar esse problema (SILVA FILHO, 1988), como a Comissão Especial para Restauração da Serra do Mar (SÃO PAULO, 1989), de caráter interdisciplinar e interinstitucional, que teve resultados consideráveis, porém anos mais tarde os estudos que vinham sendo realizados foram interrompidos.
A carência e a necessidade de estudos sobre as espécies vegetais ocorrentes em áreas sujeitas a deslizamentos, como ferramenta de uso na recuperação dessas áreas, foram enfatizadas por Oliveira (1998). Tais estudos se apresentariam, na prática, como um protocolo de levantamento e análise de dados, de forma a constituir um campo de conhecimento sistemático, prospectivo e integrado (MARTINS, 2004). Nesse sentido, o processo de regeneração das ravinas reflete a interação da dinâmica da colonização com atividades hidroerosivas das vertentes (CASTRO JUNIOR et al., 1997). Entre os desafios, na busca de alternativas de recuperação e contenção de encostas, destaca-se a necessidade do entendimento sobre o processo de colonização natural,

\footnotetext{
${ }^{1}$ Recebido em 09.06.2008 e aceito para publicação em 14.10.2009.

${ }^{2}$ Instituto de Botânica, IBt, Brasil. E-mail: <njunior@ibot.sp.gov.br>, <josemarcobarbosa@terra.com.br>e < mar.ambiente@gmail.com>.

${ }^{3}$ Universidade Estadual Paulista Júlio de Mesquita Filho, UNESP, Brasil. E-mail: <victorjc@rc.unesp.br>.
} 
considerando aspectos da ecofisiologia das espécies vegetais herbáceo-arbustivas. Almeida e Souza (1997) já destacavam também a importância de estudos de cunhos florístico e fitossociológico para subsidiarem ações de manejo da comunidade, possibilitando traçar estratégias de conservação, além do fato de, segundo Ferreira et al. (2007), o sucesso das ações de recuperação de áreas degradadas depender diretamente, entre outros fatores, da escolha correta das espécies vegetais.

Diante do exposto, este trabalho objetivou monitorar, ao longo de um ano, a colonização natural de áreas de encosta degradadas por espécies de plantas herbáceo-arbustivas, no intuito de subsidiar trabalhos de recuperação de áreas de encosta na serra do Mar.

\section{MATERIAL E MÉTODOS}

\subsection{Definição das áreas experimentais e caracterização da região}

Foram realizadas visitas a diversos locais de encosta na serra do Mar, no litoral sul do Estado de São Paulo, mais precisamente na Baixada Santista, a fim de se elegerem as áreas experimentais. Para a escolha das áreas, foram levados em conta o grau de degradação, o agente degradador (neste caso, poluição atmosférica) e a viabilidade de desenvolvimento da proposta de estudo. Ao final desse processo, foram eleitas duas áreas experimentais: Área 1 - situada no Polo Industrial de Cubatão; e Área 2 - situada próximo à rodovia Anchieta, distantes aproximadamente $10 \mathrm{~km}$ entre si. Dessa forma, estabeleceu-se um gradiente de distância do Polo Industrial de Cubatão, do perfil da vegetação e de altitude (Figura 1).

O clima na Baixada Santista, segundo São Paulo (2004), apresenta taxa alta de umidade relativa durante todo o ano, bem como índices pluviométricos também elevados (SILVA FILHO, 1988). Durante o período de monitoramento das áreas, a chuva acumulada na Baixada Santista foi de 1.734,6 mm e a temperatura teve média de $23,5^{\circ} \mathrm{C}$ (CIIAGRO, 2009). A vegetação predominante na região, reconhecida originalmente como mata pluvial (COUTINHO, 1962), floresta ombrófila densa (SÃO PAULO, 1999), conhecida como Mata Atlântica (FERNANDES, 1998), tem expressão fisionômica e composição florística bem diversificadas, quando analisados os seus padrões fitogeográficos.

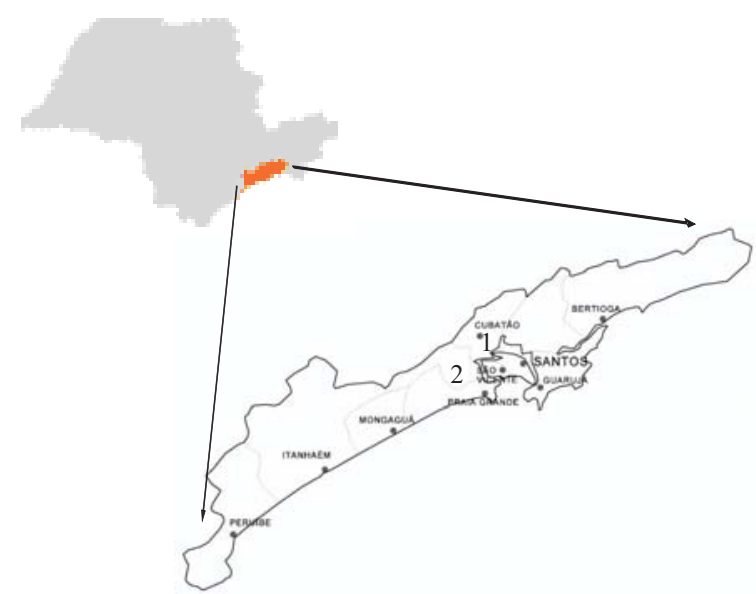

Figura 1 - Mapa do Estado de São Paulo, com ênfase na Baixada Santista, onde estão indicadas as duas áreas experimentais (TALAMONI e JAHNEL, 2002).

Figure 1 - Map of the State of São Paulo, emphasizing the Baixada Santista where the two experimental areas are indicated (TALAMONI e JAHNEL, 2002).

O Polo Industrial de Cubatão, apesar do controle por parte dos órgãos ambientais de fiscalização, em especial da CETESB, nas últimas décadas, ainda emite valores consideráveis de poluentes na atmosfera e, quanto mais próximos do vale, alguns trechos da vegetação ainda apresentam sinais de degradação evidentes (DOMINGOS et al., 1997; 2000).

\section{2) Área situada no Polo Industrial de Cubatão (Área 1)}

Esta área localiza-se próximo ao polo de fertilizantes de Cubatão, SP, mais precisamente na área da Fosfértil/ Ultrafértil Indústria e Comércio de Fertilizantes Ltda. (Complexo Industrial de Piaçaguera), situada na estrada Engenheiro Plínio de Queiroz, s/n, Jardim São Marcos, em Cubatão, SP. A área experimental situava-se nas coordenadas geográficas $23^{\circ} 49^{\prime} 50,2^{\prime \prime} \mathrm{S}$ e $46^{\circ} 23^{\prime} 02,6^{\prime \prime}$ $\mathrm{W}$, a uma altitude de aproximadamente $50 \mathrm{~m}$. As coordenadas geográficas nas duas áreas foram obtidas com o uso de aparelho de GPS.

O relevo local, com declividade sempre superior a $45^{\circ}$, é resultado das características estruturais e clima locais, numa condição topográfica que não favorece a dispersão de poluentes (SILVA FILHO, 1988). O solo, classificado como litossolo (SÃO PAULO, 1989), apresenta evidentes sinais de alteração, pela exposição aos poluentes locais. A ravina, em especial, possui perfil linear e cerca de $15 \mathrm{~m}$ de largura por $20 \mathrm{~m}$ de comprimento, com a formação de uma faixa plana em sua base, oriunda de sucessivos processos erosivos. A declividade era em torno dos $75^{\circ}$. 
A mata local, de perfil secundário, encontrava-se em avançado estágio de regeneração, não mais sendo típica a presença de "paliteiros”, termo que se referia às árvores destituídas das folhas que acabavam por morrer e iniciar o processo erosivo. Nas áreas onde antes se localizavam as ravinas, que na década de 1980 eram muito abundantes (SÃO PAULO, 1989), havia vários indivíduos arbóreos, que acabaram por colonizar diversas dessas ravinas, porém em abundância eram encontradas, entre esses indivíduos, espécies pioneiras, o que reforça o afirmado anteriormente, ou seja, que a vegetação é secundária. Havia, ainda, diversos pontos cobertos por espécies herbáceas, como Sticherus sp. e muitas plantas exóticas ou nativas não regionais. Muitas delas foram introduzidas durante as tentativas de recuperação por parte da Comissão Especial para Restauração da Serra do Mar ou colonizaram naturalmente, já que a área distava cerca de 300 m da sede da empresa, que por sua vez recebia grande fluxo de veículos e funcionários.

\section{3. Área situada próxima à rodovia Anchieta (Área 2)}

Esta área estava localizada a $50 \mathrm{~m}$ da rodovia Padre Manuel da Nóbrega, km 55, no cruzamento com a rodovia Anchieta, Município de Cubatão, SP, nas coordenadas geográficas $23^{\circ} 57^{\prime} 3^{\prime \prime} \mathrm{S}$ e $46^{\circ} 23^{\prime} 15^{\prime \prime} \mathrm{W}$, pertence à Gafor Ltda. (CNPJ nº 61.288.940/0009-70). A altitude, na base da ravina e em relação ao nível do mar, era de cerca de $30 \mathrm{~m}$. Na base do morro, a empresa realizava atividades de transporte e armazenamento de cargas que tinham como destino, principalmente, o Porto de Santos. Devido à ação da poluição, à declividade (cerca de $75 \%$ ) e à ocupação da base do morro, há cerca de 5 anos havia ocorrido um deslizamento que recobriu grande parte do pátio da empresa, de onde foram retiradas cerca de 450 carretas de terra, provocando grandes prejuízos à empresa. Desde então, não houve fechamento na cobertura vegetal dessa ravina, apenas a estabilização parcial do solo.

O perfil da encosta estava ligado, principalmente, às sucessivas erosões superficiais que ocorriam no local. Após o primeiro grande deslizamento, foram formadas duas superfícies côncavas voltadas para dentro, dando um aspecto de " $U$ ", com um canal de escoamento no centro que, ao longo dos anos, formou grande depósito de sedimentos na base da ravina. Pelo deslocamento, foi exposto o subsolo, ou seja, restou o horizonte B do solo litólico com condições de fertilidade muito baixas. A ravina apresentava-se com cerca de $10 \mathrm{~m}$ de largura por $12 \mathrm{~m}$ de comprimento.
Com o tempo, na dinâmica de colonização da ravina o solo passou a ser coberto por vegetação pioneira herbáceo-arbustiva, que aumentou a infiltração no solo e reduziu, sem eliminar, o escoamento superficial e, consequentemente, o processo erosivo local.

Apesar de o entorno da ravina ser formado pela vegetação primária de floresta ombrófila densa, a proximidade com as rodovias fez que naturalmente a área fosse dominada por vegetação herbáceo-arbustiva exótica.

\subsection{Instalação das parcelas nas áreas experimentais}

Para a marcação das parcelas, foram utilizadas estacas de madeira de 50 × $4 \mathrm{~cm}$ de madeira, entrelaçadas por fitilho plástico. A marcação deu-se aleatoriamente por meio de sorteio. As estacas foram instaladas da base em direção ao ápice, de forma que aquelas instaladas pudessem servir de sustentação para atingir as partes mais elevadas. Quando necessário, foi amarrada uma corda estática em uma árvore firme acima do ápice da ravina, que percorria toda a sua extensão, no intuito de auxiliar na sustentação. O trabalho foi realizado sempre por três pessoas, estando uma delas localizada abaixo da ravina, a outra na base e a terceira efetuava a fixação das estacas. Foram estabelecidas 100 parcelas de $1 \mathrm{~m}^{2}$ na Área 1, enquanto na Área 2 foram instaladas apenas 50 parcelas, devido ao fato de o trecho não comportar mais unidades.

\subsection{Monitoramento}

No mês de janeiro foi realizada a análise florística dos indivíduos localizados nas parcelas. O material botânico das espécies amostradas foi coletado de, pelo menos, três indivíduos distintos, sempre que possível férteis, segundo recomendação de Fidalgo e Bononi (1989). Cada uma das espécies amostradas foi devidamente identificada e então coletados seus dados biométricos. Para aquelas espécies cujo perfil era caracterizado por crescimento vertical, formando copa, foram coletados dados de altura (cm), largura da maior copa e a medida de copa perpendicular a essa. Com base nesses dois últimos dados de projeção de copa, foi obtida a área de copa $\left(\mathbf{c m}^{2}\right)$, através da fórmula da elipse (SANTOS JUNIOR, 2000). Para as espécies cujo perfil de crescimento não possibilitava a obtenção dos dados acima referidos, foi adotada, dependendo dela, a expansão (cm), para as espécies rasteiras rizomatosas; ou cobertura de solo $\left(\mathbf{c m}^{2}\right)$, 
para as espécies recobridoras de solo ou que formavam as chamadas “touceiras”. Em todas as espécies foi calculado o índice de cobertura do solo (\%) (SANTOS et al., 1997), representado pela porcentagem que dada espécie ocupava de sua referida parcela, bem como os parâmetros fitossociológicos frequências absoluta e relativa e densidades absoluta e relativa, segundo fórmulas descritas por Vuono (1985). A similaridade florística entre as áreas amostradas foi obtida através do cálculo do Coeficiente de Sorensen (S) (MAGURRAN, 1988).

Após a identificação e medição das espécies localizadas no interior das parcelas, foram retiradas todas as plantas, mas as parcelas marcadas foram mantidas. Foi limpa, também, uma faixa de cerca de $1 \mathrm{~m}$ no entorno das parcelas, no intuito de não permitir que a área fosse colonizada por órgãos subterrâneos das plantas do entorno.

Ao longo de um ano, as três áreas foram visitadas mensalmente, sendo monitorada a recolonização das ravinas, através do registro das espécies que surgiram em cada uma das parcelas. De forma similar ao realizado na primeira etapa, as espécies foram herborizadas e encaminhadas à Seção de Curadoria do Herbário do Instituto de Botânica para posterior identificação taxonômica. Algumas das plantas não tiveram tempo suficiente para adquirir porte adulto ou entrar em fase reprodutiva e, consequentemente, em período fértil, para permitir a identificação completa.

Como forma de caracterização dos aspectos físicoquímicos do solo, foram coletadas amostras desse solo na faixa degradada e na faixa remanescente de vegetação conservada no entorno da área, em duas profundidades (0 a 20 e 20 a $40 \mathrm{~cm}$ ), com o uso de trado.

\section{RESULTADOS}

Comparando as duas áreas e enfocando as características do solo, notou-se que o solo das duas áreas possuía propriedades bem distintas. Na análise da fertilidade do solo da Área 1 (Tabela 1), alguns dados chamam atenção e destoam do padrão considerado “normal” para os solos da região. Inicialmente, os teores de cálcio são exageradamente altos. Também se destacam os dados referentes ao enxofre que, assim como o cálcio, apresenta valores impraticáveis em solos naturais.

Tabela 1 - Análise físico-química do solo das duas áreas experimentais, coletado em duas profundidades e em locais conservados e degradados.

Table 1 - Physical-chemistry soil analysis of two experimental areas, collected in two depths and in conserved and degraded places.

\begin{tabular}{|c|c|c|c|c|c|c|c|c|}
\hline \multirow[t]{2}{*}{$\begin{array}{l}\text { Áreas/ profundidades } \\
\text { de coleta }\end{array}$} & \multicolumn{2}{|c|}{$\begin{array}{c}\text { Área } 1 \\
\text { conservada }\end{array}$} & \multicolumn{2}{|c|}{$\begin{array}{c}\text { Área } 1 \\
\text { degradada }\end{array}$} & \multicolumn{2}{|c|}{$\begin{array}{c}\text { Área } 2 \\
\text { conservada }\end{array}$} & \multicolumn{2}{|c|}{$\begin{array}{c}\text { Área } 2 \\
\text { degradada }\end{array}$} \\
\hline & $0-20$ & $20-40$ & $0-20$ & $20-40$ & $0-20$ & $20-40$ & $0-20$ & $20-40$ \\
\hline Parâmetros & $\mathrm{cm}$ & $\mathrm{cm}$ & $\mathrm{cm}$ & $\mathrm{cm}$ & $\mathrm{cm}$ & $\mathrm{cm}$ & $\mathrm{cm}$ & $\mathrm{cm}$ \\
\hline $\mathrm{P}$ resina $\left(\mathrm{mg} / \mathrm{dm}^{3}\right)$ & 37 & 10 & 13 & 5 & 4 & 4 & 7 & 5 \\
\hline M.O. $\left(\mathrm{g} / \mathrm{dm}^{3}\right)$ & 22 & 22 & 33 & 24 & 63 & 36 & 3 & 1 \\
\hline $\mathrm{pH}\left(\mathrm{CaCl}_{2}\right)$ & 4,0 & 3,8 & 4,0 & 4,0 & 4,2 & 3,8 & 4,1 & 4,2 \\
\hline $\mathrm{K}\left(\mathrm{mmol}_{\mathrm{c}} / \mathrm{dm}^{3}\right)$ & 0,5 & 0,4 & 0,2 & 0,2 & 2,1 & 1,4 & 1,7 & 1,4 \\
\hline $\mathrm{Ca}\left(\mathrm{mmol}_{\mathrm{c}} / \mathrm{dm}^{3}\right)$ & 65 & 13 & 985 & 810 & 29 & 6 & 2 & 2 \\
\hline $\operatorname{Mg}\left(\mathrm{mmol}_{\mathrm{c}} / \mathrm{dm}^{3}\right)$ & 1 & 1 & 2 & 1 & 12 & 3 & 1 & 1 \\
\hline $\mathrm{H}+\mathrm{Al}\left(\mathrm{mmol}_{\mathrm{c}} / \mathrm{dm}^{3}\right)$ & 61 & 55 & 88 & 88 & 61 & 109 & 33 & 34 \\
\hline $\mathrm{Al}\left(\mathrm{mmol}_{\mathrm{c}} / \mathrm{dm}^{3}\right)$ & 17,5 & 17,6 & 17,0 & 17,4 & 8,7 & 20,3 & 16,8 & 17,5 \\
\hline $\mathrm{SB}\left(\mathrm{mmol}_{\mathrm{c}} / \mathrm{dm}^{3}\right)$ & 66,5 & 14,4 & 987,2 & 811,2 & 43,1 & 10,4 & 4,7 & 4,4 \\
\hline $\mathrm{CTC}\left(\mathrm{mmol}_{\mathrm{c}} / \mathrm{dm}^{3}\right)$ & 127,5 & 69,4 & 1075,2 & 899,2 & 104,1 & 119,4 & 37,5 & 38,4 \\
\hline V (\%) & 52 & 25 & 92 & 90 & 41 & 9 & 12 & 11 \\
\hline $\mathrm{B}\left(\mathrm{mg} / \mathrm{dm}^{3}\right)$ & 0,15 & 0,19 & 0,51 & 0,24 & 1 & 0,6 & 0,03 & 0,01 \\
\hline $\mathrm{Cu}\left(\mathrm{mg} / \mathrm{dm}^{3}\right)$ & 0,9 & 0,8 & 1,7 & 1,2 & 1,9 & 1,3 & 0,8 & 0,5 \\
\hline $\mathrm{Fe}\left(\mathrm{mg} / \mathrm{dm}^{3}\right)$ & 180 & 190 & 240 & 190 & 170 & 210 & 4 & 3 \\
\hline $\operatorname{Mn}\left(\mathrm{mg} / \mathrm{dm}^{3}\right)$ & 17,5 & 10,7 & 19,5 & 8,7 & 36 & 10,4 & 1,6 & 1,2 \\
\hline $\mathrm{Zn}\left(\mathrm{mg} / \mathrm{dm}^{3}\right)$ & 0,8 & 0,5 & 1,4 & 1,4 & 8 & 2,9 & 0,3 & 0,2 \\
\hline $\mathrm{S}\left(\mathrm{mg} / \mathrm{dm}^{3}\right)$ & 490 & 170 & 520 & 590 & 21 & 47 & 110 & 130 \\
\hline
\end{tabular}

R. Árvore, Viçosa-MG, v.34, n.2, p.267-276, 2010 
Nessa mesma tabela, é possível notar que na Área 2 foram observados, de imediato, baixos valores de matéria orgânica. Chamam atenção também os valores baixos de cálcio, potássio e magnésio e os bem elevados de enxofre, muito acima do convencional em solos da região.

Numa análise geral, notou-se diversidade baixa de espécies, considerando tratar-se de uma área em colonização natural, tendo sido observadas 20 espécies pertencentes a 14 famílias botânicas, ao longo de todo o período (Tabelas 2 e 3).

Pode-se observar, através do índice de similaridade florística de Sorensen, que as áreas 1 e 2 apresentavam composição vegetal com 63\% de similaridade.

O maior valor médio do Índice de Cobertura do Solo (ICS) (Tabela 2) foi obtido por Cecropia pachystachya Trecul, Miconia cabucu Hoehne e Ricinus communis L., todas com 100\% de ocupação média de suas parcelas. Na sequência, acima de 50\% de ICS, apareceram Sticherus bifidus (Willd.) Ching, Brachiaria sp., Nephroleps multiflora (Roxb.) C. V. Morton e Impatiens holstii Engel., sendo apenas esta última localizada onde se formou um "platô". Analisando os dados referentes à dinâmica vegetal, a frequência absoluta foi maior nas pteridófitas S. bifidus e Lycopodiella cernua (L.) Pic. Serm. Ainda com destaque, foram encontradas $N$. multiflora, Tibouchina clavata (Pers.) Wurdack. e Blechnum serrulatum Rich. T. clavata, S. bifidus e L. cernua; além de muito frequentes, são espécies com valores altos de densidade absoluta, aqui expressos em plantas/ha.

A avaliação da composição vegetal e da colonização na Área 2 (Tabela 3) também levou em consideração os mesmos parâmetros de biometria e de fitossociologia das espécies. Nessa área, as espécies com maior ICS foram C. pachystachya e R. communis. S. bifidus e $N$. multiflora também apresentaram altos valores médios de ICS. Os dados de frequência absoluta indicaram que as espécies com maior aparição nas parcelas amostradas foram Brachiaria mutica (Forsk.) Stapf. (22\%), S. bifidus (16\%) e T. clavata (14\%). Essas espécies também apresentaram os maiores valores médios de densidade absoluta com, respectivamente, 2.600, 1.600 e 3.600 plantas/ha. Ainda com relação ao fator densidade, $N$. multiflora também foi abundante, com cerca de 1.000 plantas/ha, porém com ocorrência mais agregada e em trechos mais declivosos.

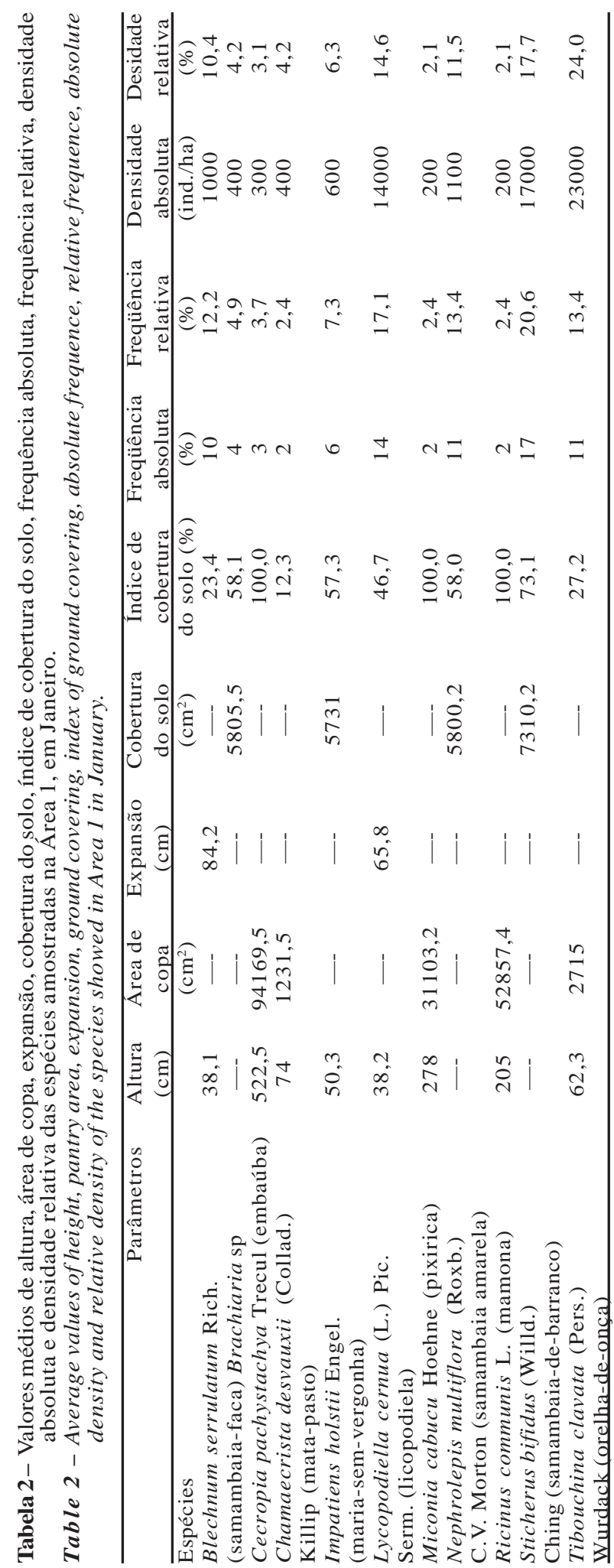

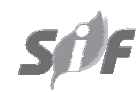

R. Árvore, Viçosa-MG, v.34, n.2, p.267-276, 2010 


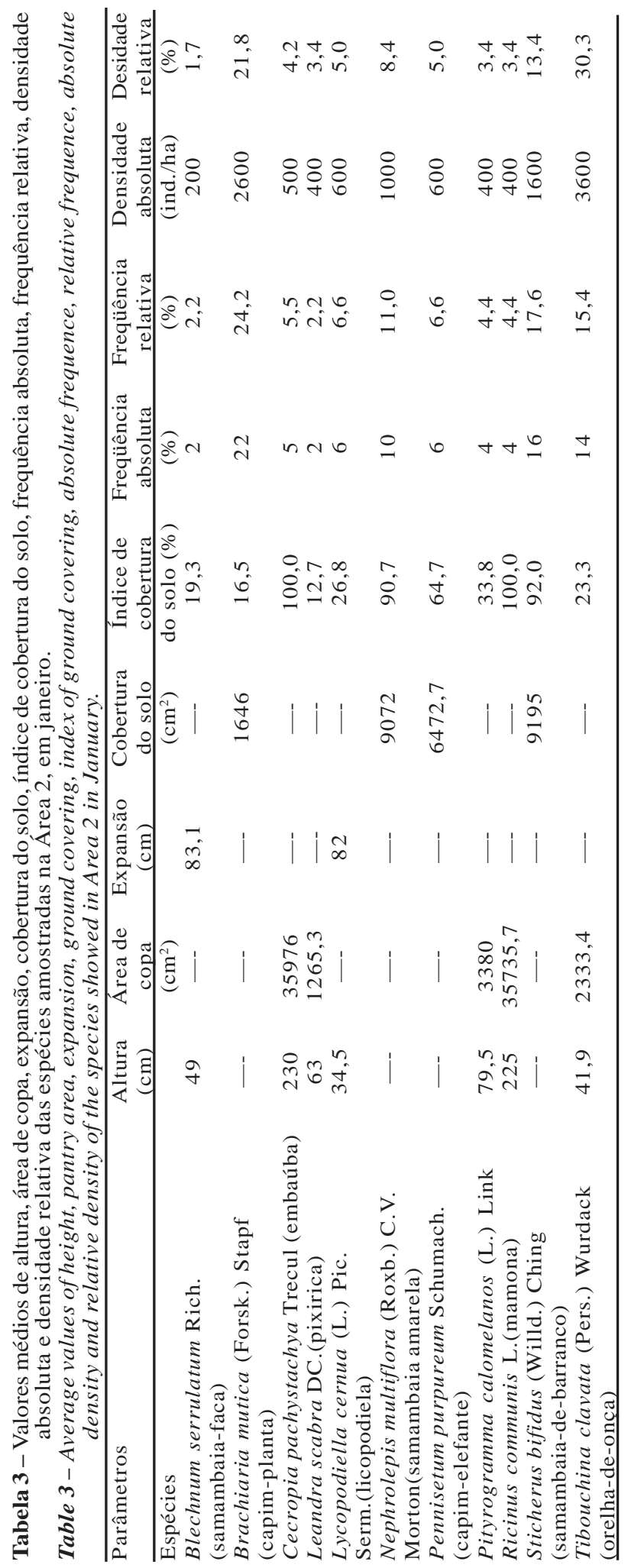

Na Área 2, passou-se a não haver acréscimo no número de espécies com número menor de parcelas lançadas (Figura 2), em que foram estabelecidas apenas 50 parcelas. Na Área 1, não houve mais o acréscimo no número de espécies a partir da $90^{\circ}$ parcela.

Após a limpeza das áreas e com a eliminação de todas as plantas, verificou-se que as mais abundantes em ambas as áreas, nos primeiros três meses de avaliação, foram T. clavata e Brachiaria sp. (Figura 3ab). Essas plantas aumentaram consideravelmente a frequência no $12^{\circ}$ mês, ou seja, no meio do verão, período no qual estavam férteis.

No caso da Área 1, as demais espécies que reapareceram (L. cernua, I. holstii, Chamaecrista desvauxii (Collad.) Killip. e C. pachystachya), no final do ano de avaliação, não chegaram a ocupar sequer $10 \%$ das parcelas lançadas. Pilea muscosa Lindl., Paspalum sp., Cordia chacoensis Chodat. e Bidens sp. não apareceram no levantamento inicial e aqui o fizeram com frequência baixa (Figura 3a). Entre as cinco espécies pteridófitas presentes inicialmente na área, apenas $L$. cernua reapareceu, mas com pequena frequência.

Com base na Figura 3b, é possível notar que $T$. clavata e B. mutica, espécies que já haviam aparecido no levantamento anterior, reapareceram com destaque, em frequência, em relação às demais espécies na Área

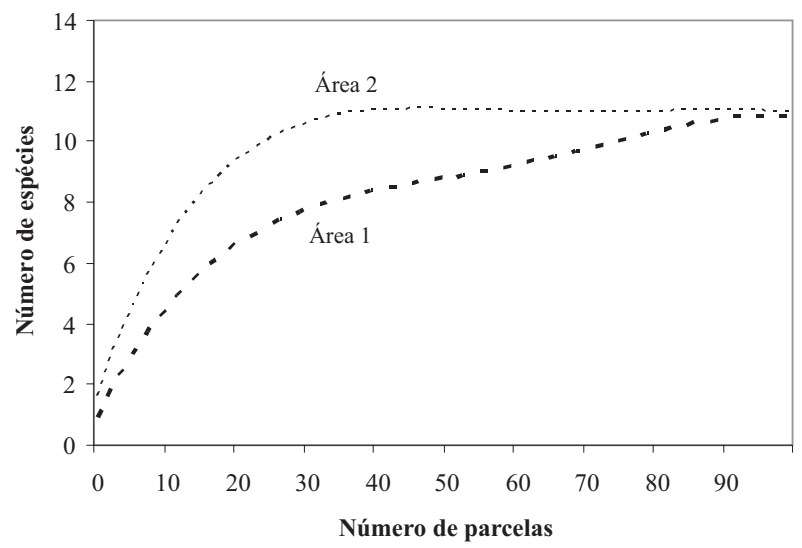

Figura 2 - Curva cumulativa de espécies em função do número de parcelas lançadas (Área $\mathrm{Iy}=-0,001 \mathrm{x}^{2}+0,1831 \mathrm{x}$ $+2,4932, \mathrm{R}^{2}=0,918$; Área II $\mathrm{y}=-0,0018 \mathrm{x}^{2}+$ $\left.0,2308 \mathrm{x}+4,2119, \mathrm{R}^{2}=0,890\right)$.

Figure 2-Cumulative curve of species in function of the launched parcels. (Area I $y=-0.001 x^{2}+0.1831 x$ $+2.4932, R^{2}=0.918$; Área II $y=-0.0018 x^{2}+$ $\left.0.2308 x+4.2119, R^{2}=0.890\right)$. 

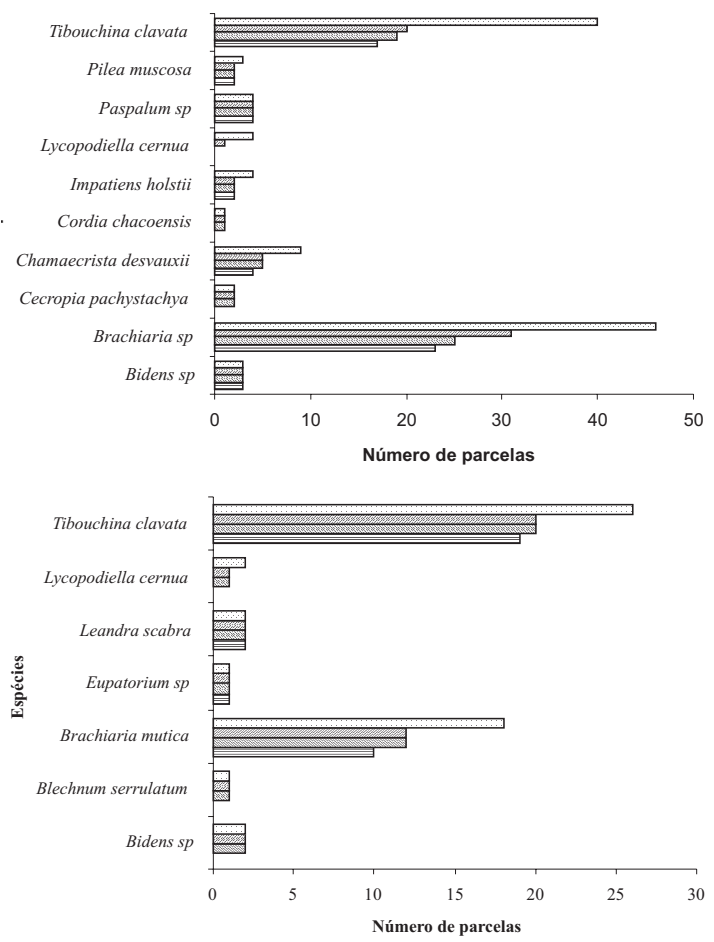

Figura 3 - Número de parcelas com a presença das espécies encontradas aos 3, 6, 9 e 12 meses de avaliação nas áreas 1 (a) e 2 (b).

Figure 3 - Number of parcels with the presence of the found species after 3, 6, 9 and 12 months in area 1 (a) and 2 (b).

2. O maior crescimento apresentado por ambas se deu logo na primeira avaliação ( $3^{\circ}$ mês), período pós-verão. Leandra scabra DC., Eupatorium sp. e Bidens sp. surgiram na área, porém em quantidade pequena. Da mesma forma que na Área 1, na área das pteridófitas, inicialmente presentes, reapareceram apenas $L$. cernua e B. serrulatum, porém em pequena quantidade. No décimo mês de avaliação, ou seja, no mês de novembro, houve deslizamento na área, que promoveu a perda de nove parcelas.

\section{DISCUSSÃO}

Naturalmente no solo, o cálcio, que foi encontrado com altos valores na Área 1, já compete com o magnésio e o potássio no que diz respeito à sua disponibilização à planta. Agravando essa situação, esses dois últimos estão em quantidade muito baixa. Esses valores apresentados comprometeriam de imediato o desenvolvimento vegetal que, apesar de não quantificado neste estudo, deve ser ressaltado. Os valores altos de cálcio justificam, também, os índices altos de somas de base.
Os dados observados na Área 2 refletem as condições do solo em que houve a ocorrência de deslizamento: baixos teores de matéria orgânica e de fertilidade em geral, já que, nessa área, foi encontrado subsolo exposto após a erosão.

Para melhor compreensão sobre a caracterização das áreas, é necessário entender os parâmetros fitossociológicos e biométricos das plantas, que devem ser considerados conjuntamente para a precisão maior da análise. Os dados referentes à biometria das plantas, apesar de servirem para o conhecimento da sua estrutura e porte, pouco representam em informações por si só, já que há espécies com as mais diversificadas formas de crescimento. Contudo, as características biométricas devem auxiliar a compreensão e avaliação dos parâmetros apresentados referentes à fitossociologia. Dessa forma, foi dada ênfase ao índice de cobertura do solo (ICS), ou seja, à projeção de toda a biometria da planta no sentido da ocupação da sua referida parcela.

A similaridade florística entre as áreas pode ser devida à semelhança entre o meio físico das áreas. Castro Junior et al. (1997) afirmaram que a intensidade e a composição de espécies na colonização são frutos do tamanho, forma, declividade, posição, tempo sucessional e interferências na ravina.

As características químicas do solo encontradas na área 1, provavelmente a causa do desenvolvimento vegetal bem reduzido, condizem com o observado por Domingos et al. (2000), que, em trabalhos realizados em local próximo, afirmaram, com base na produção de serapilheira, que o desenvolvimento vegetal foi menor em comparação com os padrões normais da região. Com relação aos valores elevados de enxofre (Tabela 1), em comparação com valores obtidos em locais isentos ou com baixa poluição, há fortes indícios da presença de material de origem externa contaminando a área.

Na Área 2 foram encontrados valores baixíssimos de matéria orgânica (Tabela 1). Para Moreira e Costa (2004), em processos erosivos que acometem a faixa superficial do solo, dano, de imediato, se dá sobre a matéria orgânica e, consequentemente, na microbiota e ciclagem de nutrientes do local. Esses autores ainda encontraram elevados valores de enxofre, provavelmente como consequência do efeito da poluição, já que os óxidos de enxofre estão entre os poluentes mais emitidos na região.

R. Árvore, Viçosa-MG, v.34, n.2, p.267-276, 2010 
A ocupação média de $100 \%$ das parcelas por parte de Cecropia pachystachya, Ricinus communis e Miconia cabucu na Área 1 e das duas primeiras também na Área 2 é justificável, pelo fato de essas espécies possuírem porte arbóreo e, consequentemente, em razão de sua copa recobrir praticamente toda a parcela. Sticherus bifidus, Brachiaria sp., Nephroleps multiflora e Impatiens holstii apresentaram acima de 50\% de cobertura do solo na Área 1, tendo ocorrido o mesmo nas duas primeiras na Área 2, indicando ser espécies muito agressivas na invasão de ambientes antropizados. Entre essas, chama a atenção a presença de Brachiaria sp., espécie exótica, mas que foi utilizada nas ações de semeadura ainda na década de 1980, o que justifica sua presença (SÃO PAULO, 1989). A presença em abundância das pteridófitas Sticherus bifidus e Lycopodiella cernua também foi verificada na colonização de ravinas do Parque Nacional da Tijuca, por Castro Junior et al. (1997).

A estabilização no número acumulado de espécies a partir da amostragem efetuada que ocorreu inicialmente na Área 2 (Figura 2) era esperada, pois se trata da menor área quando comparada com a Área 1.

Após a limpeza das áreas, verificou-se que as plantas mais abundantes, em ambas as áreas, nos primeiros três meses de avaliação foram Tibouchina clavata e Brachiaria sp. (Figura 3ab), resultado similar ao ocorrido no $1^{\circ}$ levantamento. Essas plantas aumentaram consideravelmente a frequência no $12^{\circ}$ mês, ou seja, no meio do verão, período em que estão férteis.

As espécies mais abundantes no primeiro levantamento também foram aquelas com maior presença após a limpeza de ambas as áreas, o que reforça o fato de serem espécies muito agressivas na colonização de áreas que sofreram intervenção.

No caso específico da Área 1, algumas espécies não presentes no $1^{\circ}$ levantamento, como Pilea muscosa, Paspalum sp., Cordia chacoensis e Bidens sp., provavelmente estavam presentes no entorno da ravina e eram colonizadoras, porém não se mostraram boas competidoras e, com o início da colonização por parte de outras espécies mais agressivas, acabaram por desaparecer. No caso específico das pteridófitas, grupo que no primeiro levantamento estava presente na área 1 com cinco representantes, apenas Lycopodiella cernua reapareceu, ainda que com pequena frequência. Esse grupo vegetal, como depende da colonização do ambiente por meio de esporos, gera, ainda, estágios intermediário, temporário e dependente da água no seu desenvolvimento (gametófito) e, provavelmente, leve mais tempo para invadir um local (RAVEN et al., 2001).

Na Área 2, Tibouchina clavata e Brachiaria mutica reapareceram com destaque, o que reforça sua agressividade. Leandra scabra, Eupatorium sp. e Bidens sp. surgiram nessa área após a limpeza do local. A primeira delas era reconhecidamente colonizadora de bordas de mata e clareiras em florestas ombrófilas, principalmente na faixa litorânea. As duas outras eram, segundo Lorenzi (2000), plantas daninhas comuns em beiras de estrada, como é o caso dessa área, muito próxima da rodovia Anchieta. Eupatorium sp. incluise entre as invasoras mais agressivas, em parte atribuídas à produção de grande número de sementes que germinam em abundância e com facilidade (AMARAL-BAROLI, 1998). Da mesma forma que na Área 1, nesta, das pteridófitas inicialmente presentes, reapareceram apenas Lycopodiella cernua e Blechnum serrulatum, espécies que, após invadirem determinado local, se propagam por intermédio da expansão dos rizomas.

\section{CONCLUSÃO}

Ambas as áreas de encosta estudadas foram colonizadas, inicialmente, por espécies herbáceas exóticas ou nativas não regionais muito agressivas e com grande potencial de estabilização do solo.

Esse perfil de colonização reforça a forte pressão de urbanização que se encontram as escarpas da serra do Mar, principalmente aquelas próximas à Baixada Santista.

Apesar disso, possuem elevado potencial de regeneração, o que permite técnicas de recuperação baseadas na indução da colonização natural, desde que o comprometimento da área com o processo erosivo seja superficial.

\section{REFERÊNCIAS}

ALMEIDA, D. S.; SOUZA, A. L. Florística de um fragmento de Floresta Atlântica, no município de Juiz de Fora, Minas Gerais. Revista Árvore, v. 21, n. 2, p. 221-230, 1997.

AMARAL-BAROLI, A. Germinação de sementes de Baccharis dracunculifolia DC., Eupatorium laevigatum Lam. E Galinsoga parviflora Cav. (Asteraceae). 1998. 102 f. Tese (Doutorado) - Departamento de Botânica, Universidade Estadual Paulista “Júlio de Mesquita Filho”, Rio Claro, 1998. 
CASTRO JUNIOR, E. DE; ROCHA LEÃO, O. M.; TURETTA, A. P. D.; CRUZ, E. S.; BALESDANT, F. C.; SENRA, L. C.; COELHO NETTO, L. Estudo da colonização espontânea e resultantes hidroerosivas em cicatrizes de movimento de massa: cicatriz vista do Almirante Parna Tijuca, RJ. In: SIMPÓSIO NACIONAL DE RECUPERAÇÃO DE ÁREAS DEGRADADAS, 3., 1997, Ouro Preto. Anais... Ouro Preto: SOBRADE, 1997. p. 259 - 269.

\section{CIIAGRO(CENTRO INTEGRADODE} INFORMÇÃOESAGROMETEOROLÓGICAS). Boletim climático Santos (boletim personalizado). Campinas, Instituto Agronômico de Campinas. Disponível em: http:// www.iac.sp.gov.br/ciiagro. Acesso em 30 junho 2009.

COUTINHO, L. M. Contribuição ao conhecimento da ecologia da Mata Pluvial Tropical. Boletim da Faculdade de Filosofia, Ciência e Letras, v. 18, p. 1-219, 1962.

DOMINGOS, M.; LOPES, M. I. M. S.; VUONO, Y. S. DE. Nutrient cycling disturbance in Atlantic Forest sites affected by air pollution coming from the industrial complex of Cubatão, Southeast Brazil. Revista Brasileira de Botânica, v.23, n.1, p.77-85, 2000.

DOMINGOS, M.; MORAES, R. M.; VUONO, Y. S. DE; ANSELMO, C. E. Produção de serapilheira e retorno de nutrientes em um trecho de Mata Atlântica secundária na Reserva Biológica de Paranapiacaba. Revista Brasileira de Botânica, v.20, n.1, p.91-96, 1997.

FERNANDES, A. Fitogeografia brasileira. Fortaleza: Multigraf, 1998.

FERREIRA, W. C.; BOTELHO, S. A.; DAVIDE A. C.; FARIA, J. M. R. Avaliação do crescimento do estrato arbóreo de área degradada revegetada à margem do Rio Grande, na Usina Hidrelétrica de Camargos, MG. Revista Árvore, v. 31, n. 1, p. 177-185, 2007.

FIDALGO, O.; BONONI, V. L. R. (Coord.)

Técnicas de coleta, preservação e herborização de material botânico. São Paulo: Instituto de Botânica, 1989. (Série Documentos).
LORENZI, H. Plantas daninhas do Brasil: terrestres, aquáticas, parasitas e tóxicas. 3. ed. Nova Odessa: Instituto Plantarum de Estudos da Flora Ltda, 2000.

MAGURRAN, A. E. Ecological diversity and its measurement. Princeton: Princeton University Press, 1988.

MARTINS, F. R. O papel da fitossociologia na conservação e na bioprospecção. In: CONGRESSO NACIONAL DE BOTÂNICA, 55., 2004, Viçosa. Anais... Viçosa: SBB/UFV, 2004. CD-ROM.

MOREIRA, A.; COSTA, D. G. Dinâmica de matéria orgânica na recuperação de clareiras na floresta amazônica. Pesquisa Agropecuária brasileira, v.39, n.10, p.1013-1019, 2004.

OLIVEIRA, R. R. O uso de dados de inventários florísticos como ferramenta para compreensão da funcionalidade da Mata Atlântica. In: SIMPÓSIO DE ECOSSISTEMAS BRASILEIROS, 4., 1998, Águas de Lindóia. Anais... São Paulo: ACIESP, 1998. v. 5, p. $153-161$.

POMPÉIA, S.L.; PRADELLA, D.Z.A.; MARTINS, S.E.; SANTOS, R.C.; DINIZ, K.M. A semeadura aérea na Serra do Mar em Cubatão. Ambiente, v.3, n.1, p.13-18, 1989.

RAVEN, P.H.; EVERT, R.F.; EICHHORN, S.E.. Biologia vegetal. $6^{a}$ edição. Rio de Janeiro: Guanabara Koogan, 2001.

SANTOS JUNIOR, N. A. Estabelecimento de espécies florestais nativas em sistema de semeadura direta. 2000. $97 \mathrm{f}$. Dissertação (Mestrado) - Departamento de Ciências Florestais, Universidade Federal de Lavras, Lavras, 2000.

SANTOS, M. DOS; ORLANDINI, L.; ROSADO, S. C. S.; OLIVEIRA FILHO, A. T. DE. Evolução da cobertura vegetal herbáceo-arbustiva em dunas de rejeito de mineração, em função da idade e irrigação. In: SIMPÓSIO NACIONAL DE RECUPERAÇÃO DE ÁREAS DEGRADADAS, 3., 1997, Ouro Preto. Anais... Ouro Preto: SOBRADE, 1997. p. $292-296$.

SÃO PAULO (Estado). Conhecer para conservar: as unidades de conservação do Estado de São Paulo. São Paulo: Terra Virgem/SMA, 1999.

R. Árvore, Viçosa-MG, v.34, n.2, p.267-276, 2010 
SÃO PAULO (Estado). Recomposição da vegetação da Serra do Mar em Cubatão. São Paulo: Instituto de Botânica/SMA, 1989.

SÃO PAULO (Estado). Relatório de qualidade do ar do estado de São Paulo: 2003. São Paulo: CETESB, 2004.

SILVA FILHO, N. L. DA. Recomposição da cobertura vegetal de um trecho degradado da Serra do Mar, Cubatão, SP. Campinas: Fundação Cargill, 1988.
TALAMONI, C. D.; JAHNEL, T. C. Divisão municipal do Estado de São Paulo. São Paulo: Instituto Geográfico e Cartográfico, 2002. 1 mapa. 1:250.000. Baseado na Carta do Brasil do IBGE.

VUONO, Y. S. DE. Fitossociologia do estrato arbóreo da floresta da Reserva Biológica do Instituto de Botânica (São Paulo, SP). 1985. 213 f. Tese (Doutorado) - Instituto de Biociências, Universidade de São Paulo, São Paulo, 1985. 